\title{
The effect of prenatal betamethasone administration on postnatal ovine hypothalamic-pituitary-adrenal function
}

\author{
D M Sloboda ${ }^{1,2,3}$, T J Moss ${ }^{2,3}$, L C Gurrin ${ }^{2,3}$, J P Newnham ${ }^{2,3}$ \\ and J R G Challis ${ }^{1}$ \\ ${ }^{1}$ Canadian Institutes of Health Research Group in Fetal and Neonatal Health and Development, Departments of Physiology and Obstetrics and Gynecology, \\ University of Toronto, Toronto, Ontario, Canada \\ ${ }^{2}$ Department of Obstetrics and Gynecology, University of Western Australia, Perth, Australia \\ ${ }^{3}$ Womens and Infants Research Foundation, Perth, Australia \\ (Requests for offprints should be addressed to J R G Challis, Department of Physiology, University of Toronto, Medical Sciences Building, \\ 1 Kings College Circle, Toronto, Ontario, Canada M5S 1A8; Email: j.challis@utoronto.ca) \\ (D M Sloboda is now at the University of Western Australia)
}

\begin{abstract}
Prenatal exposure to glucocorticoids is associated with alterations in fetal growth and endocrine function. However, few studies have examined the effects of clinically relevant doses of glucocorticoids on postnatal hypothalamic-pituitary-adrenal (HPA) function. To determine the effects of maternal or fetal betamethasone administration $(0.5 \mathrm{mg} / \mathrm{kg}$ maternal or estimated fetal weight) on postnatal HPA function at 6 months and 1 year postnatal age, pregnant ewes were randomized into the following treatment groups: no treatment $(n=6)$; maternal saline $(n=6)$; single maternal betamethasone (M1) $(n=6)$; repeated maternal betamethasone (M4) $(n=6)$; fetal saline $(n=5)$; single fetal betamethasone $(n=6)$ and repeated fetal betamethasone (F4) $(n=6)$. Single injections were given at 104 days of gestation and repeated injections at 104, 111, 118 and 125 days. Lambs were born spontaneously and the ACTH and cortisol responses to i.v. corticotropinreleasing hormone $(\mathrm{CRH})(0.5 \mu \mathrm{g} / \mathrm{kg})$ plus arginine vasopressin (AVP) $(0 \cdot 1 \mu \mathrm{g} / \mathrm{kg})$ were measured at 6 months and 1 year postnatally. At 6 months postnatal age, neither maternal nor fetal prenatal betamethasone administration altered significantly the ACTH and cortisol responses to $\mathrm{CRH}+\mathrm{AVP}$. However, in animals at 1 year postnatal age,
\end{abstract}

a previous single injection of betamethasone to the mother (M1) resulted in significantly elevated basal and stimulated cortisol levels $(P<0 \cdot 05)$, without significant change in the ACTH response. In contrast, betamethasone administration to the fetus resulted in significantly attenuated ACTH responses to CRH+AVP at 1 year compared with control animals $(P<0 \cdot 05)$, but these were not associated with any significant changes in basal or stimulated cortisol levels. All control animals exhibited a significant increase in peak ACTH responses to $\mathrm{CRH}+\mathrm{AVP}$ between 6 months and 1 year postnatal age $(P<0 \cdot 05)$. After prenatal betamethasone (F4, M4) the difference in peak ACTH response between animals at 6 months and 1 year postnatal age was abolished. We conclude that in sheep between 6 months and 1 year postnatal age, HPA function undergoes developmental changes that are influenced by prenatal glucocorticoid exposure. Furthermore, the effects of glucocorticoid on postnatal HPA responses may vary according to the time in gestation that the steroid was administered, and whether it was given directly into the fetal or maternal compartment.

Journal of Endocrinology (2002) 172, 71-81

\section{Introduction}

The fetus may be exposed to different adverse circumstances during intrauterine development that lead to an increase in concentrations of circulating glucocorticoids. Prenatal stress, resulting in an elevation of maternal corticosteroid levels, has been associated with alterations in postnatal endocrine function of the infant rat and human (Takahashi \& Kalin 1991, Weinstock et al. 1992, Copper et al. 1996). Overexposure to glucocorticoid or stress during fetal life may influence the programming of different organ systems and increase the predisposition to cardiovascular and metabolic disease in later life (Langley-Evans et al. 1996, Seckl 1997, Challis et al. 1999). The enzyme 11ß-hydroxysteroid dehydrogenase $(11 \beta \mathrm{HSD})$ type 2 is expressed in the human placenta and has been suggested to influence the trans-placental transfer of maternal cortisol to the fetus, by metabolism to inactive cortisone (Stewart et al. 1994, Burton \& Waddell 1999). However, alterations in the activity or the expression of this enzyme may expose the fetus to increased levels of maternal glucocorticoid that could potentially program 
fetal responses leading to cardiovascular and/or metabolic disease in later life (Edwards et al. 1993, Seckl 1997).

Synthetic glucocorticoids, such as betamethasone, are poor substrates for the placental 11 $\beta$ HSD enzyme (Siebe et al. 1993), and pass relatively freely across the placenta into the fetal circulation. As a result, synthetic glucocorticoids are used to enhance fetal lung maturation in women at risk of preterm delivery (Liggins \& Howie 1972, Lanteri et al. 1994, Ballard \& Ballard 1995). However, relatively little is known about the longer-term effects of glucocorticoid administration on developing fetal endocrine axes and on postnatal endocrine function. In the rat, synthetic glucocorticoids given late in gestation resulted in significant elevations in basal corticosterone levels with associated hypertension in adult offspring (Levitt et al. 1996). Prenatal stress, which presumably elevates maternal and fetal endogenous corticosterone concentrations, also led to altered hypothalamic-pituitaryadrenal (HPA) and metabolic responses in postnatal life (Vallée et al. 1996). Low-dose dexamethasone infusion to the ovine fetus prevented hypoxia-induced increases in fetal plasma adrenocorticotropin (ACTH) and cortisol levels, but increased the plasma glycemic response (Fletcher et al. 2000). In addition, maternal betamethasone administration at mid-gestation resulted in elevated insulin responses to a glucose load in lambs at 6 months and 1 year after birth (Moss et al. 2000, 2001, Sloboda et al. 2000b). These observations suggest that fetal and maternal glucocorticoid exposure may have sustained effects on developing endocrine axes that lead to altered responsiveness after birth. The outcomes of administering betamethasone into the maternal or fetal compartment may be different. Maternal betamethasone administration to sheep in late pregnancy resulted in a dose-dependent decrease in lamb birth weights, whereas fetal betamethasone administration, in amounts that produced higher circulating betamethasone concentrations in the fetus, did not alter birth weights (Jobe et al. 1996, 1998). Hence there is an obvious need to examine the differential effects of prenatal maternal or fetal glucocorticoid administration on postnatal endocrine function.

Current clinical practice utilizes single or repeated administration of glucocorticoid to promote pulmonary maturity if preterm birth has not occurred, but there is little information on the long-term sequelae of these different treatment regimens. French et al. (1999) have shown recently in the human that reduced birth weight and neonatal head circumference are linked to an increased number of maternal antenatal corticosteroid doses. In sheep, maternal betamethasone administration given in amounts that mimic clinical practice, significantly altered fetal basal plasma ACTH, cortisol and cortisolbinding capacity (Sloboda et al. 2000a), but it is not known whether these effects persist into postnatal life. Synthetic glucocorticoid administration also provides, in part, a paradigm for reproducing some of the consequences of stress-induced elevations in maternal and/or fetal cortisol. Given the effects of glucocorticoid in reducing fetal weight (Reinisch et al. 1978, Johnson et al. 1981, Jobe et al. 1998) and the relationship between reduced birth weight with the metabolic syndrome $\mathrm{X}$, postnatal stress responses, and cardiovascular disease in later life (Barker 1998, Phillips et al. 1998), we hypothesized that exogenous glucocorticoid administration during pregnancy would alter postnatal HPA responsiveness. Furthermore, we reasoned that there would be different effects of maternal vs fetal administration on the HPA response. The fetal sheep HPA axis undergoes progressive maturation over the last onethird of pregnancy (Challis \& Brooks 1989) and we hypothesized that glucocorticoid administration at different times during this development phase would produce different outcomes. To begin to address these issues we have treated maternal and fetal sheep with the synthetic glucocorticoid, betamethasone, as a single injection or with repeated administration at 1 week intervals (to mimic current obstetric practice) during late pregnancy. We allowed the lambs to deliver and have measured the responsiveness of the HPA axis, as reflected in plasma $\mathrm{ACTH}$ and cortisol concentrations, to a challenge with corticotropin-releasing hormone $(\mathrm{CRH})$ and arginine vasopressin (AVP) in animals at 6 months and 1 year postnatal age.

\section{Materials and Methods}

All experimental procedures were approved by the Animal Experimentation Ethics Committee of the University of Western Australia and at the University of Toronto according to guidelines of the Canadian Council of Animal Care.

\section{Experimental procedures}

All animal experimentation was performed in Western Australia using a protocol that has been described in detail previously (Jobe et al. 1998). Pregnant ewes bearing singleton fetuses were allocated randomly to receive either no treatment (NT) or maternal or fetal injections of saline and/or betamethasone (Table 1). All treated animals (but not NT animals) were injected i.m. with $150 \mathrm{mg}$ medroxyprogesterone acetate (Depo Provera; Upjohn, Rydalmere, NSW, Australia) at 100 days of gestation to reduce pregnancy losses due to glucocorticoid treatment (Nathanielsz et al. 1988). Saline-treated animals were injected with normal saline at 104, 111, 118 and 125 days of gestation (maternal saline (MS), or fetal saline (FS)); animals treated with a single dose of corticosteroid were injected with betamethasone at 104 days of gestation and saline at 111, 118 and 125 days of gestation (maternal (M1) or fetal (F1)); animals treated with repeated doses of corticosteroid were injected with betamethasone at 104 , 
Table 1 Prenatal treatment protocol using maternal or fetal glucocorticoid

\begin{tabular}{|c|c|c|c|c|c|c|c|}
\hline & \multirow{2}{*}{$\begin{array}{l}\text { No treatment } \\
\text { control } \\
(M n=3 \\
\text { F } n=3)\end{array}$} & \multicolumn{3}{|c|}{ Maternal i.m. injections } & \multicolumn{3}{|c|}{ Direct fetal i.m. injections } \\
\hline & & $\begin{array}{l}\text { MS } \\
(M n=3 ; \\
\text { F } n=3)\end{array}$ & $\begin{array}{l}M 1 \\
(M n=3 ; \\
F n=3)\end{array}$ & $\begin{array}{l}\text { M4 } \\
(M n=4 ; \\
\text { F } n=2)\end{array}$ & $\begin{array}{l}\text { FS } \\
(M n=2 ; \\
\text { F } n=4)\end{array}$ & $\begin{array}{l}\mathrm{F} 1 \\
(\mathrm{M} n=3 ; \\
\mathrm{F} n=3)\end{array}$ & $\begin{array}{l}\text { F4 } \\
(M n=3 ; \\
\text { F } n=3)\end{array}$ \\
\hline \multicolumn{8}{|c|}{$\begin{array}{l}\text { Days of } \\
\text { gestation }\end{array}$} \\
\hline$\sim 100$ & - & MPA & MPA & MPA & MPA & MPA & MPA \\
\hline$\sim 104$ & - & Saline & Beta & Beta & Saline & Beta & Beta \\
\hline$\sim 111$ & - & Saline & Saline & Beta & Saline & Saline & Beta \\
\hline$\sim 118$ & - & Saline & Saline & Beta & Saline & Saline & Beta \\
\hline$\sim 125$ & - & Saline & Saline & Beta & Saline & Salne & Beta \\
\hline
\end{tabular}

$M P A=$ medroxyprogesterone acetate, $150 \mathrm{mg}$; Beta=betamethasone $(0.5 \mathrm{mg} / \mathrm{kg}$ ewe body weight or estimated fetal body weight); $\mathrm{M}=\mathrm{male} ; \mathrm{F}=$ female.

111, 118 and 125 days of gestation (maternal (M4) or fetal (F4)). Maternal betamethasone (Celestone Chronodose; Schering Plough, Baulkham Hills, NSW, Australia) injections were given i.m. in a dose of $0.5 \mathrm{mg} / \mathrm{kg}$ body weight; saline injections were of a comparable volume $(5-6 \mathrm{ml})$. Fetal injections were given using an established technique (Newnham et al. 1999). Briefly the ewe was held in a supine position, 70\% ethanol was applied to the ewe's abdomen as a coupling medium and the fetus was imaged using a $3.5 \mathrm{MHz}$ sector transducer (Echo Camera SSD500; Aloka, Tokyo, Japan). Betadine solution (Faulding, Welshpool, WA, Australia) was applied to the injection site and a 21-gauge $9 \mathrm{~cm}$ spinal needle (Terumo, Nedlands, WA, Australia) was introduced through the maternal abdomen into the muscle of the shoulder or rump of the fetus. Betamethasone $(0.5 \mathrm{mg} / \mathrm{kg}$ estimated fetal body weight; $1.4 \mathrm{~kg}$ at 104 days, $1.9 \mathrm{~kg}$ at 111 days, $2 \cdot 2 \mathrm{~kg}$ at 118 days, $2 \cdot 5 \mathrm{~kg}$ at 125 days) or an equal volume of saline $(1 \mathrm{ml})$ was injected by an assistant; the needle tip was imaged throughout the entire procedure. Previous studies have established that the peak fetal betamethasone concentrations, and area under the clearance curve (AUC) were approximately 3 -fold higher after fetal injection than after maternal treatment with $0.5 \mathrm{mg} / \mathrm{kg}$ betamethasone (Berry et al. 1997).

Ewes were permitted to deliver their lambs spontaneously in a field environment and were not disturbed until the time of experimentation. Lambs were raised by their mothers and were observed closely several times each day for the first few postnatal weeks. Two of the M4 lambs were raised exclusively by hand or supplemented with powdered milk (Divetalact; International Animal Health Products, Huntingwood, NSW, Australia) when it became apparent that lactation was affected in some ewes from this group. At approximately 2 months of age, the lambs were immunized, their tails cropped and males were castrated. Weaning occurred at 3 months of age. Prior to experimentation at 1 year postnatal age, estrous cycles of all female animals were synchronized with intravaginal progesterone sponges $(30 \mathrm{mg}$ flugestone acetate, ChronoGest30; Intervet Pty Ltd, Castle Hill, NSW, Australia). Six lambs from each of the seven groups were chosen at random as subjects for CRH+AVP challenge tests at 6 months and 1 year postnatal age. At 1 year, supplementation of numbers in the MS, FS, F1 and NT groups (maximum of two animals) was required due to loss such as predation that was unrelated to experimentation. These additional lambs were obtained from identically treated ewes from the original larger flock of animals (Table 1).

$C R H+A V P$ challenges at 6 months and 1 year postnatal age

At both 6 months and 1 year postnatal age, lambs underwent aseptic surgery to implant femoral arterial and venous catheters (halothane anesthesia, $1-2 \%$ in $\mathrm{O}_{2}$, following induction with ketamine/xylazine) and were allowed at least 3 days to recover before performing $\mathrm{CRH}+\mathrm{AVP}$ challenges. Catheters were removed after the completion of experiments. Food was withdrawn $12 \mathrm{~h}$ before challenges, but the animals were allowed free access to water. Basal arterial blood samples $(5 \mathrm{ml})$ were drawn at 30 and $15 \mathrm{~min}$ and immediately before the administration of an i.v. bolus of $0.5 \mu \mathrm{g}$ ovine $\mathrm{CRH}+0.1 \mu \mathrm{g}$ AVP (Bachem, Torrance, CA, USA) per $\mathrm{kg}$ lamb weight followed by a $10 \mathrm{ml}$ saline flush. Arterial samples $(5 \mathrm{ml})$ were collected at 5, 10, 20, 30, 60, 90, 120, 180 and 240 min after the CRH+AVP administration, centrifuged for $10 \mathrm{~min}$ at $4{ }^{\circ} \mathrm{C}$ and the plasma was collected and stored at $-80{ }^{\circ} \mathrm{C}$. All challenges were administered between 0800 and $0900 \mathrm{~h}$ in order to minimize the impact of circadian variability on measurements of plasma ACTH and cortisol.

\section{Measurement of plasma ACTH and cortisol}

Plasma immunoreactive ACTH concentrations were measured using a commercial RIA kit (Incstar, Stillwater, MN, USA) previously validated for use in the fetal sheep 
Table 2 Basal ACTH $(\mathrm{pg} / \mathrm{ml})$ and cortisol $(\mathrm{ng} / \mathrm{ml})$ levels (means \pm S.E.M.) at 6 months and 1 year postnatal age following prenatal maternal and fetal betamethasone administration

\begin{tabular}{|c|c|c|c|c|}
\hline & \multicolumn{2}{|l|}{ Six months } & \multicolumn{2}{|l|}{ One year } \\
\hline & ACTH & Cortisol & ACTH & Cortisol \\
\hline \multicolumn{5}{|c|}{$\begin{array}{l}\text { Treatment } \\
\text { groups }\end{array}$} \\
\hline NT & $18 \cdot 0 \pm 5 \cdot 2$ & $5 \cdot 8 \pm 1 \cdot 3$ & $27 \cdot 9 \pm 1 \cdot 8$ & $4 \cdot 3 \pm 0 \cdot 9$ \\
\hline MS & $16 \cdot 4 \pm 3 \cdot 8$ & $3 \cdot 9 \pm 0.7$ & $32 \cdot 1 \pm 2 \cdot 7$ & $5 \cdot 3 \pm 0 \cdot 9$ \\
\hline M1 & $8 \cdot 2 \pm 3 \cdot 5$ & $3 \cdot 7 \pm 0 \cdot 7$ & $25 \cdot 9 \pm 2 \cdot 7$ & $8 \cdot 5 \pm 0.9 *$ \\
\hline M4 & $17 \cdot 0 \pm 3 \cdot 5$ & $5.9 \pm 0.6$ & $32 \cdot 1 \pm 3 \cdot 0$ & $3 \cdot 6 \pm 0 \cdot 9$ \\
\hline FS & $32 \cdot 0 \pm 10 \cdot 7$ & $4 \cdot 4 \pm 0 \cdot 5$ & $40 \cdot 4 \pm 5 \cdot 4$ & $6 \cdot 3 \pm 1 \cdot 1$ \\
\hline F1 & $22 \cdot 4 \pm 9 \cdot 5$ & $6 \cdot 2 \pm 1 \cdot 3$ & $26 \cdot 4 \pm 5 \cdot 4$ & $5 \cdot 3 \pm 1 \cdot 1$ \\
\hline $\mathrm{F} 4$ & $14 \cdot 1 \pm 9 \cdot 5$ & $5 \cdot 6 \pm 1 \cdot 2$ & $27 \cdot 8 \pm 7 \cdot 0$ & $5 \cdot 5 \pm 1 \cdot 4$ \\
\hline
\end{tabular}

${ }^{*} P<0.05 \mathrm{M} 1$ versus NT, MS and M4. Lack of difference $(P>0 \cdot 05)$ between NT controls, and MS or FS treatment control animals.

(Norman et al. 1985). The intra-assay coefficient of variation was $4 \cdot 5 \%$, and the inter-assay $4 \%$. The mean assay sensitivity was $15 \mathrm{pg} / \mathrm{ml}$. The ACTH antibody cross reacted $<0.01 \%$ with $\alpha$ - and $\beta$-melanocyte-stimulating hormone, $\beta$-endorphin and $\beta$-lipotrophin. Plasma cortisol concentrations were quantified by RIA after extraction with diethyl ether. The antibody characteristics have been described previously (Jeffray et al. 1995). The intra-assay coefficient of variation was $6 \%$, the inter-assay $15 \%$.

\section{Statistical analysis}

Results are expressed as means \pm S.E.M. A comparison of group means was made using ANOVA (SAS, Cary, NC, USA) and S-PLUS (Mathsoft, Seattle, WA, USA). In all cases, basal values represent the mean value of the three samples drawn prior to the administration of the CRH+AVP injection (time 0). The experimental design did not allow us to examine possible sex-specific effects on outcome variables. The numbers of male and female offspring were distributed between different treatment groups (Table 1) such that there was no bias to either sex within any group. Assessment of responses in individual animals indicated overlap between data points for male and female fetuses (data not shown) within treatments, and results are presented as mean values for each group, as a whole.

In order to assess the overall effect of prenatal betamethasone on the response patterns to the challenge, we calculated the AUCs for each group between 5 and $240 \mathrm{~min}$ after CRH+AVP. This calculation permitted us to resolve occasional missing values where sample collection may have been impaired. To understand the effects of prenatal betamethasone on both postnatal ACTH and cortisol responses to the challenge and alterations due to age, we compared the observed peak ACTH and cortisol values at 6 months postnatal age with values at 1 year postnatal age, within each treatment group, using
Student's $t$-test (Sigma Stat, Chicago, IL, USA). We also evaluated whether age-related changes in ACTH and cortisol peak responses were different following betamethasone administration, by taking the observations from each animal and analyzing differences using a one-way ANOVA (Sigma Stat). In all cases the level of statistical significance was taken to be $P<0 \cdot 05$.

\section{Results}

Effects of prenatal maternal or fetal betamethasone administration on responses at 6 months postnatal age

At 6 months postnatal age, basal plasma ACTH and cortisol concentrations were similar in all groups following prenatal maternal betamethasone and were similar between NT, FS and MS groups (Table 2). Animals responded to the $\mathrm{CRH}+\mathrm{AVP}$ challenge with peak ACTH levels $(150-250 \mathrm{pg} / \mathrm{ml})$ at approximately $5 \mathrm{~min}$ but there was no effect of treatment on peak ACTH values or on the AUC. Peak cortisol values $(\sim 30-40 \mathrm{ng} / \mathrm{ml})$ were achieved at $\sim 20 \mathrm{~min}$ after injection but there were no significant effects of treatment on cortisol responses (data not shown).

Basal ACTH and cortisol concentrations were not different in the F1 and F4 groups from FS controls (Table 2) and there was no effect of prenatal fetal betamethasone treatment on peak or AUC values for ACTH or cortisol after fetal betamethasone treatment (data not shown).

\section{Effect of prenatal maternal or fetal betamethasone} administration on responses at 1 year postnatal age

At 1 year postnatal age, basal plasma ACTH concentrations were similar between control groups and amongst all groups following maternal or fetal betamethasone 

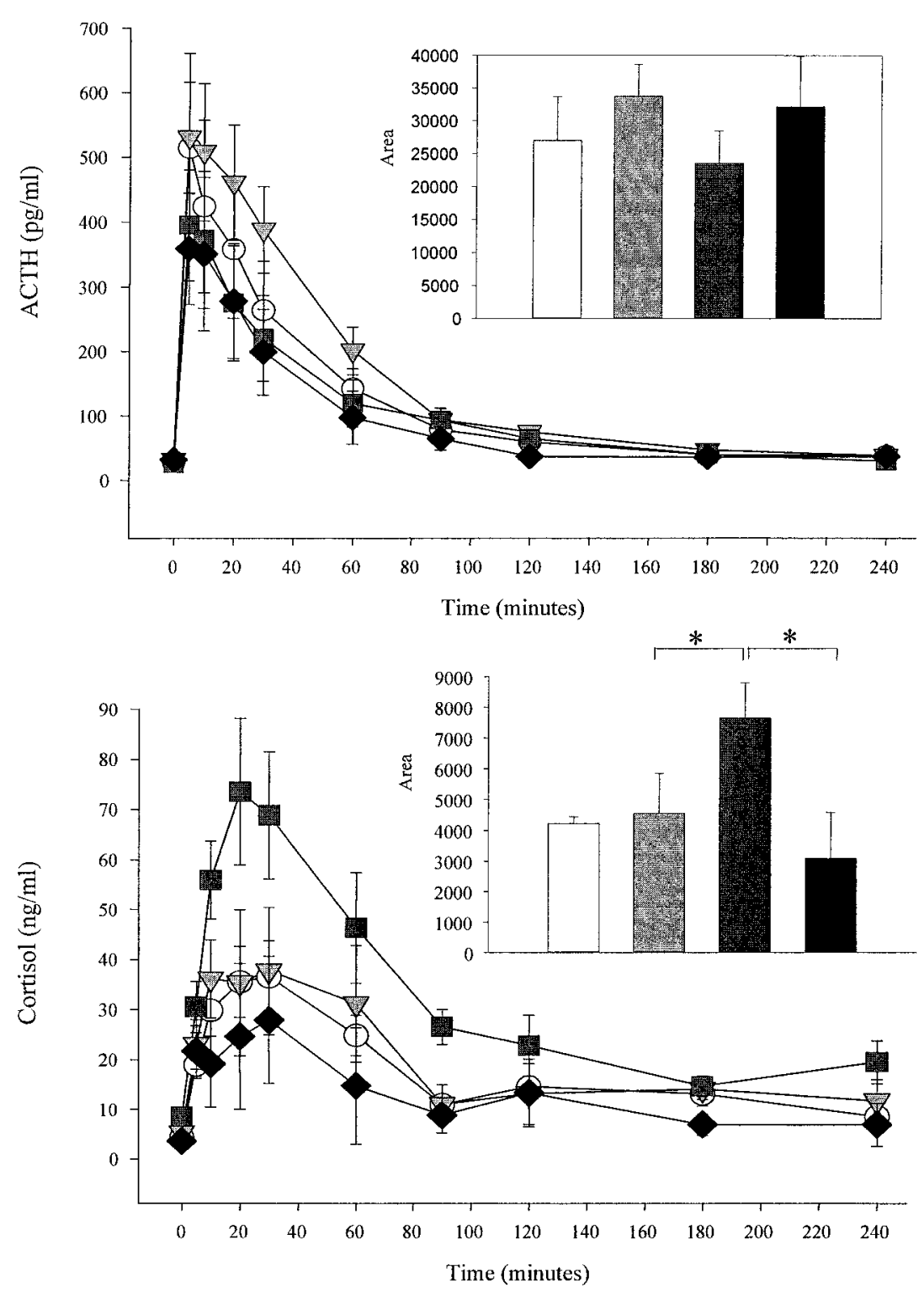

Figure $1 \mathrm{ACTH}$ (upper panel) and cortisol (lower panel) response patterns to CRH+AVP at 1 year postnatal age following prenatal administration of maternal betamethasone. $\bigcirc \mathrm{NT}$; $\nabla \mathrm{MS} ; \square \mathrm{M} 1 ;$ M4. The inset histograms show AUCs for the groups in the same order. Means \pm S.E.M. ${ }^{*} P<0 \cdot 05$.

treatment (Table 2). Basal plasma cortisol, however, was significantly higher in the M1 group compared with MS and M4 groups of animals (Table 2; $P<0 \cdot 05$ ).

All animals at 1 year postnatal age from maternal betamethasone treatments responded to the CRH+AVP i.v. bolus with peak ACTH levels at approximately $5 \mathrm{~min}$ and peak cortisol at approximately 20 min after administration (Figs 1 and 2). The ACTH response patterns and the AUC for ACTH were not significantly affected by prenatal maternal betamethasone administration (Fig. 1).
However, the peak and AUC for the cortisol values in the M1 group were significantly greater than in the MS and M4 groups of animals (Fig. 1; $P<0 \cdot 05$ ).

All animals treated with fetal betamethasone in utero responded to the $\mathrm{CRH}+\mathrm{AVP}$ challenge with peak $\mathrm{ACTH}$ values at $5-10 \mathrm{~min}$ and peak cortisol at $20-40 \mathrm{~min}$. The ACTH response in F1 and F4 animals was consistently lower than that in the FS group and the AUCs for ACTH for the F1 and F4 groups were significantly lower than that of the FS group (Fig. 2; $P<0 \cdot 05$ ). Plasma cortisol 

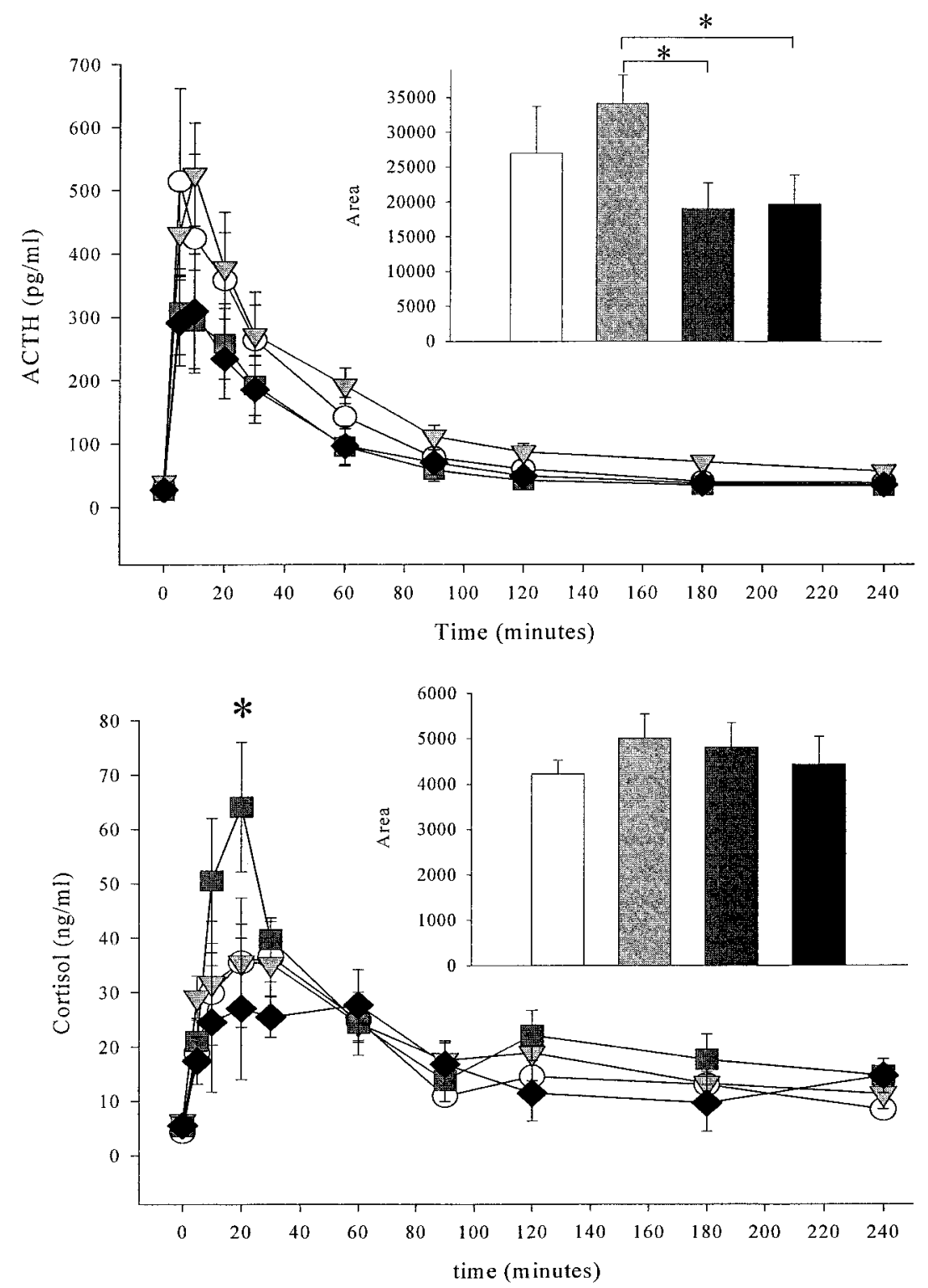

Figure 2 ACTH (upper panel) and cortisol (lower panel) response patterns to CRH+AVP at 1 year postnatal age following prenatal administration of fetal betamethasone. $\bigcirc \mathrm{NT}$; $\nabla \mathrm{FS}$; $\square$ F1; F4. The inset histograms show AUCs for the groups in the same order. Means \pm S.E.M. ${ }^{*} P<0 \cdot 05$.

concentrations at $20 \mathrm{~min}$ were significantly higher in the F1 group $(P<0 \cdot 05)$ but there were no significant differences in the overall AUC for cortisol between groups (Fig. 2).

Comparison of the ACTH and cortisol responses between 6 months and 1 year postnatal age

Peak ACTH and cortisol values in response to $\mathrm{CRH}+\mathrm{AVP}$ at 6 months and 1 year postnatal age are illustrated in Figs 3 and 4. NT, MS and FS animals exhibited significantly higher peak ACTH values at 1 year postnatal age compared with 6 months postnatal age (Figs 3 and 4; $P<0 \cdot 05$ ). In contrast, peak cortisol values in untreated (control) animals between 6 months and 1 year postnatal age were unchanged, with the exception of FS animals (Figs 3 and 4). The ACTH and cortisol AUCs following CRH+AVP at 6 months and 1 year postnatal age were consistent with the measurements of peak hormone concentrations in that ACTH values were higher 

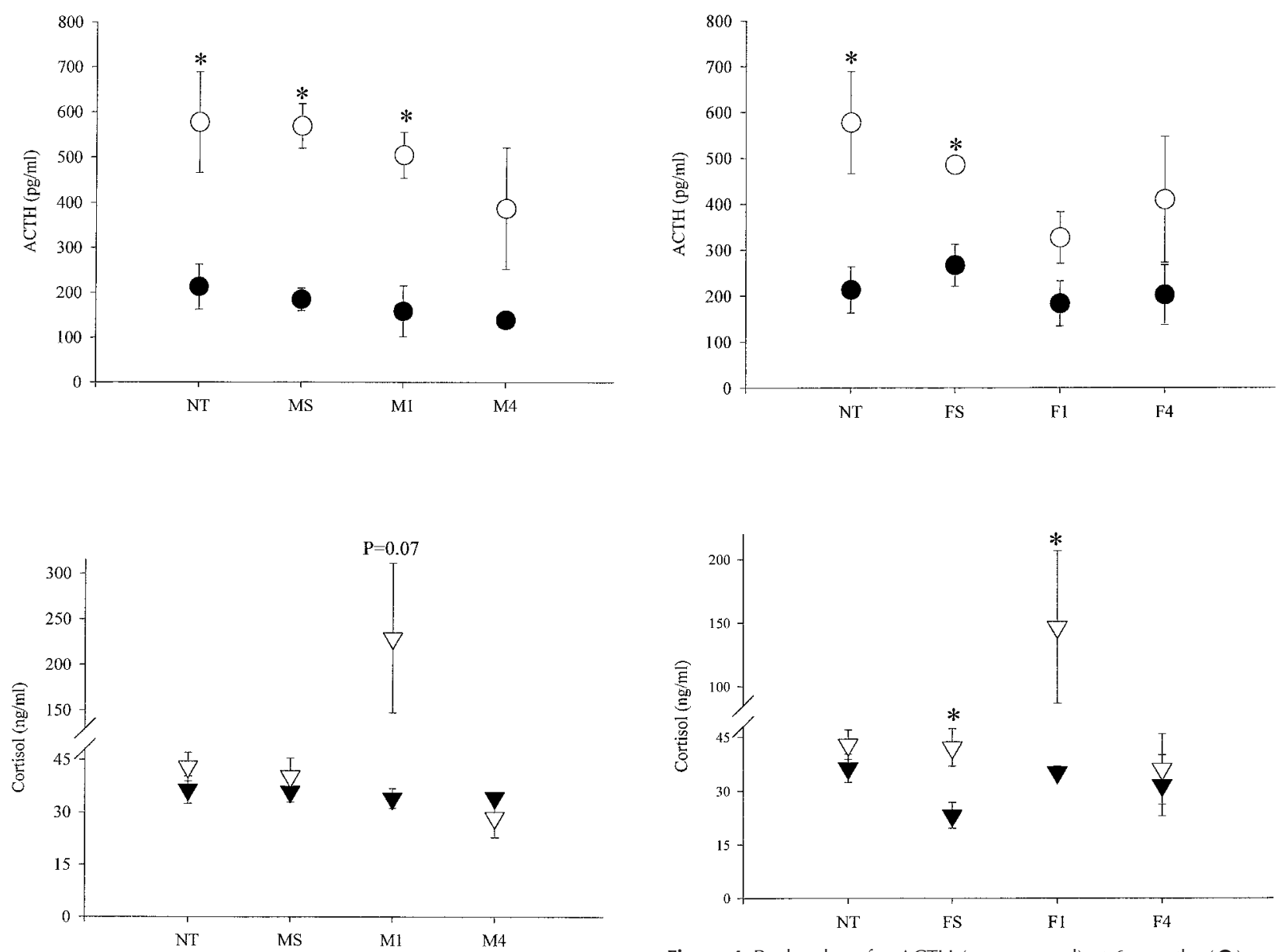

Figure 3 Peak values for ACTH (upper panel) at 6 months and 1 year $(\bigcirc)$ postnatal age and for cortisol (lower panel) at 6 months $(\boldsymbol{\nabla})$ and 1 year $(\nabla)$ postnatal age following prenatal maternal betamethasone administration. Means \pm S.E.M. ${ }^{*} P<0 \cdot 05$, 6 months vs 1 year; other values not statistically different $(P>0 \cdot 05)$ from each other.

at 1 year postnatal age but were not associated with any change in cortisol AUC (Figs 5 and 6).

The differences between peak ACTH values and ACTH AUC at 6 months and 1 year were somewhat attenuated after M4 but not M1 betamethasone treatment (Figs 3 and 5), but were completely abolished in both F1 and F4 betamethasone groups of animals (Figs 4 and 6). The lack of difference in peak or AUC cortisol seen generally between control animals at 6 months or 1 year postnatal age was unaffected by maternal betamethasone, although in M1 group animals both peak and cortisol AUC values approached significance. Similarly, there were no significant differences in peak or cortisol AUC values between 6 months and 1 year in the F4 animals but 1 year values were significantly higher than those at 6 months in the F1 group of animals.

Figure 4 Peak values for ACTH (upper panel) at 6 months ( and 1 year $(\bigcirc)$ postnatal age and for cortisol (lower panel) at 6 months $(\boldsymbol{\nabla})$ and 1 year $(\nabla)$ postnatal age following prenatal fetal betamethasone administration. Means \pm S.E.M. ${ }^{*} P<0 \cdot 05$, 6 months vs 1 year.

\section{Discussion}

We have shown that betamethasone administered to sheep during the last two-thirds of pregnancy altered HPA responsiveness in the offspring at up to 1 year postnatal age. The outcomes varied according to the time in gestation when the synthetic glucocorticoid was given, and whether it was administered to mother or fetus. Furthermore, we found that the responsiveness of the HPA axis was altered between 6 months and 1 year postnatal age, and these age-related changes were influenced by prenatal betamethasone administration.

We used bolus CRH and AVP administration to assess changes in plasma ACTH and cortisol as indices of pituitary and adrenal responsiveness following prenatal treatment with glucocorticoids. This method of assessment 

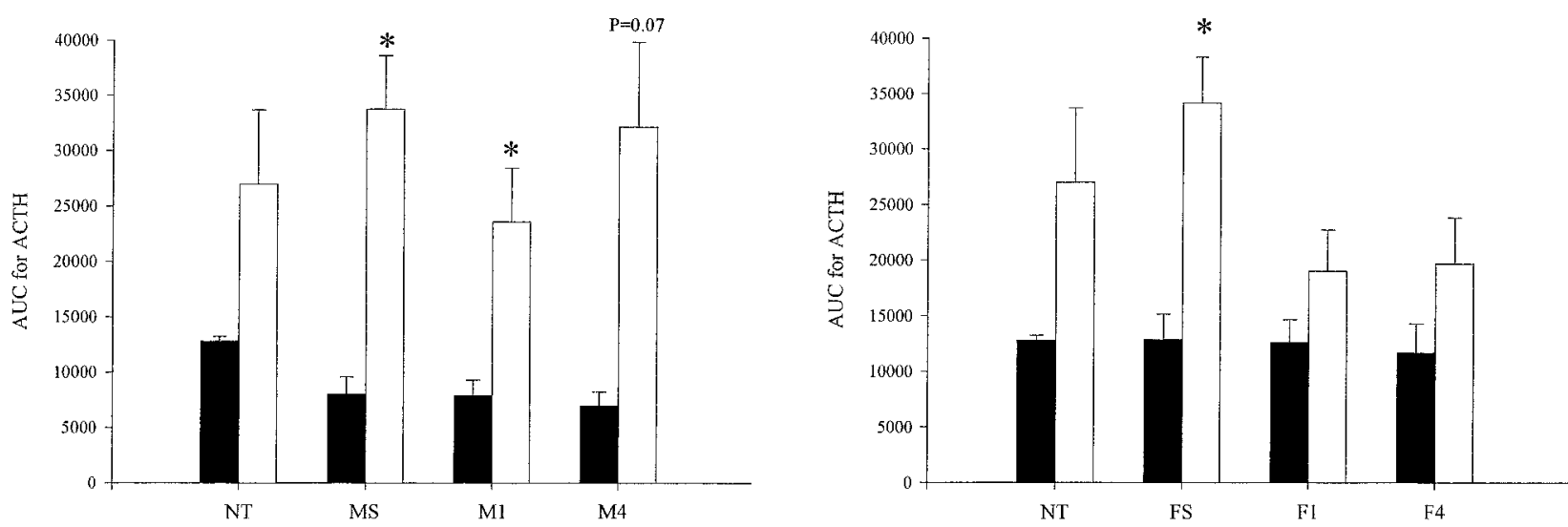

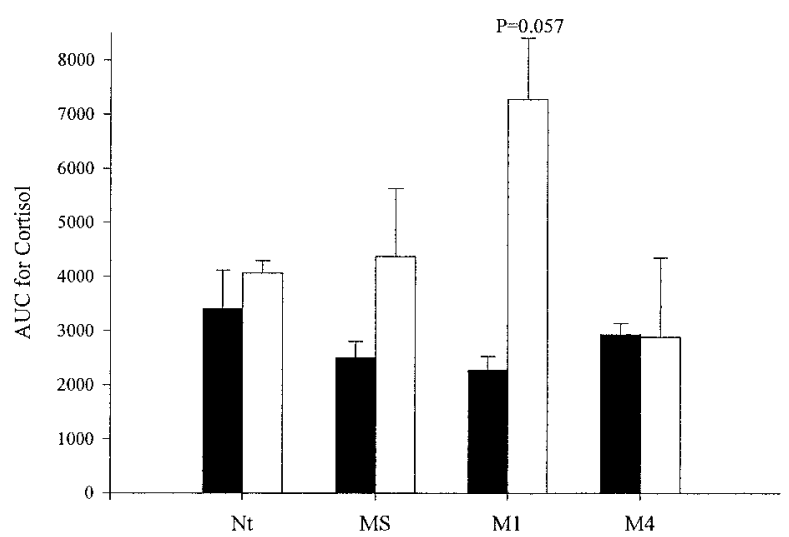

Figure 5 AUCs for ACTH (upper panel) and cortisol (lower panel) at 6 months (filled bars) and 1 year (open bars) postnatal age following maternal betamethasone administration. Means \pm S.E.M. ${ }^{*} P<0 \cdot 05,6$ months vs 1 year.

has been utilized previously in fetal (Norman \& Challis 1987, Hawkins et al. 1999) and adult (Brooks \& Challis 1989) sheep. We did not measure changes in metabolic clearance rate of ACTH or cortisol in the lambs at the two postnatal ages, but are not aware of measurements showing changes in clearance that would alter interpretation of our assessment of plasma hormone concentrations.

We were aware that postnatal HPA responses in male and female offspring could be different, but future studies with larger numbers of animals would be required to assess this. Lingas et al. (1999) have shown sex-dependent differences in cortisol responses to an ACTH challenge in postnatal guinea pigs subjected to undernutrition during pregnancy. We ensured that there were male and female fetuses in each treatment group to avoid bias in the results based on sex, and found that within each group there was overlap between data points regardless of sex. Hence, while we cannot exclude an influence of sex on HPA responsiveness in postnatal sheep up to 1 year postnatal age, the differences in responses that we report are evident, and presumably greater than any proposed gender influence.

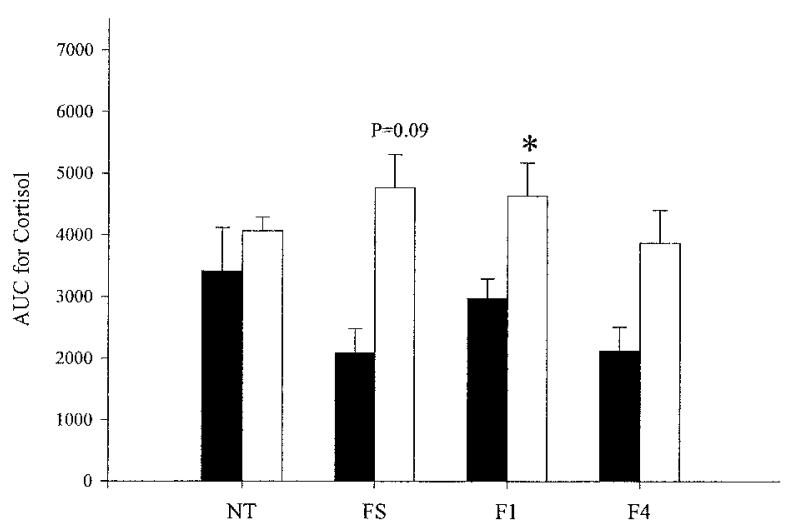

Figure 6 AUCs for ACTH (upper panel) and cortisol (lower panel) at 6 months (filled bars) and 1 year (open bars) postnatal age following fetal betamethasone administration. Means \pm S.E.M. ${ }^{*} P<0 \cdot 05,6$ months vs 1 year.

In the current studies, control animals treated with maternal or fetal saline, as well as the treatment animals, received progesterone during pregnancy. The NT animals did not receive progesterone. The observation that there were no significant differences between saline and NT controls allows one to conclude that progesterone treatment per se during pregnancy did not influence the subsequent HPA responses after birth. Postnatal females were synchronized at 1 year postnatal age to eliminate influences of stages of the estrous cycle, and males were castrated at 2 months of age to eliminate influences of postnatal testosterone. Thus, the consistency of responses at 1 year postnatal age demonstrates a remarkable robustness to the influence of glucocorticoid exposure during pregnancy. These effects, for example on the cortisol response in M1 animals at 1 year are clearly quite discrete. It is very likely that exposure to betamethasone on day 104 reflects a particular window in development that hypothetically could be augmented, unaltered or reversed by later glucocorticoid administration. We do know that this is a dynamic period in maturation of the fetal HPA axis (Challis \& Brooks 1989). Our results suggest that a specific 
influence of glucocorticoid given on day 104 may be attenuated by further glucocorticoid given at 1 week intervals to up to 3 weeks later in pregnancy.

The present observations in animals at 1 year postnatal age are consistent with previous studies that have reported elevated basal corticosterone levels in rats treated prenatally with maternal dexamethasone late in gestation (Levitt et al. 1996). Uno et al. (1994) have shown that prenatal treatment with maternal dexamethasone resulted in elevated basal and post-stress cortisol levels in juvenile monkeys. These observations were associated with a reduction in fetal hippocampal pyramidal cells (Uno et al. 1990, 1994). Many studies have reported significant alterations in glucocorticoid receptor (GR) and mineralocorticoid receptor (MR) mRNA levels in the HPA axis following prenatal glucocorticoid exposure (Uno et al. 1990, Levitt et al. 1996), thus linking glucocorticoid exposure with alterations in negative feedback at the level of the hippocampus. In our study, a single dose of prenatal maternal betamethasone (M1) resulted in significant elevations in basal and stimulated cortisol concentrations at 1 year postnatal age, whereas multiple doses (M4) resulted in a modest attenuation in stimulated cortisol levels. It has been reported previously that administration of as little as one dose of $0.5 \mathrm{mg} / \mathrm{kg}$ dexamethasone to the pregnant rhesus monkey significantly depleted fetal hippocampal neurons (Uno et al. 1990). It is possible that one dose of prenatal betamethasone given at a critical time point in hippocampal or hypothalamic development could alter the GR pattern of expression and alter the set point of HPA negative feedback function. This effect is altered in the M4 sheep. Previously we found that three injections of maternal betamethasone significantly increased fetal pituitary but not hypothalamic GR mRNA levels (Sloboda et al. 2000a), consistent with altered negative feedback function at least at the level of the pituitary. It is not known whether pituitary, hypothalamic or hippocampal GR or MR is altered in the current series of animals. Previous studies have linked increases in fasting cortisol levels in 64-year-old men to a reduction in birth weight, high blood pressure, glucose intolerance, elevated plasma triglycerides and insulin resistance (Phillips et al. 1998). These observations further support the hypothesis that the HPA axis is vulnerable to in utero 'reprogramming' and that glucocorticoids play a key role in these intrauterine events.

It appears likely that prenatal betamethasone administration results in alterations in adrenal responsiveness irrespective of changes in circulating ACTH. The ovine fetal adrenal undergoes a growth period at 40-90 days of gestation and is capable of secreting cortisol at this time (Boshier \& Holloway 1989, Wintour et al. 1995). This is followed by a period of relative quiescence (90-120 days of gestation) characterized by a decrease in responsiveness until 120 days gestational age, when adrenal sensitivity increases to a maximum at term (Rose et al. 1982, Boshier
\& Holloway 1989, Wintour et al. 1995). This increase in responsiveness has been associated with an increase in ACTH receptor mRNA levels (Fraser et al. 2001). It is possible that an early single exposure to prenatal betamethasone at 104 days of gestation increased ACTH receptors and/or steroidogenic enzymes during this period of relative quiescence in a way that permanently increased the set point of adrenal responsiveness. It has been reported previously that cortisol regulates ACTH activation of fetal adrenal function late in gestation (Challis et al. 1985). In addition, dexamethasone treatment of ovine adrenocortical cells increased mRNA levels of all three ACTH receptor transcripts in a dose-dependent manner (Picard-Hagen et al. 1997). Multiple maternal betamethasone injections (M4), on the other hand, could have decreased ACTH receptors in the adrenal, consistent with a decrease in adrenal responsiveness. Previous studies have shown that fetal sheep exposed to modest undernutrition early in gestation exhibited a reduction in both pituitary and adrenal responsiveness to i.v. CRH+AVP and to hypoxia late in gestation (Hawkins et al. 1998, 1999).

This study is the first to show that fetal betamethasone administration causes alterations in postnatal ovine HPA function. Prenatal fetal betamethasone treatment suppressed pituitary responsiveness at 1 year postnatal age compared with controls. This effect could be exerted at the levels of the hypothalamus or pituitary; for example, an increase in GR in pituitary corticotropes should increase negative feedback and reduce the secretion of ACTH (Matthews \& Challis 1997, Sloboda et al. 2000a). The fact that animals treated with fetal betamethasone (F1 and F4) responded with values of cortisol similar to controls, in the presence of reduced levels of ACTH, suggests also an increase in adrenal responsiveness. Previous reports have shown that rats exposed prenatally to a low-protein diet had blunted diurnal variation in plasma ACTH levels without any alterations in corticosterone levels. It was suggested that prenatal undernutrition results in a hyperresponsiveness to ACTH in the adrenal of the offspring (Langley-Evans et al. 1996). Although the mechanisms are not understood it is apparent that prenatal fetal and prenatal maternal betamethasone administration may work through different pathways.

We have shown that the stimulated HPA axis function in the sheep undergoes a developmental maturation between the postnatal ages of 6 months and 1 year. NT, MS and FS animals exhibited a similar significant increase in peak ACTH responses to CRH+AVP from 6 months to 1 year postnatal age. This observation suggests an increase in pituitary responsiveness with age. Prenatal betamethasone abolished this maturational increase in peak $\mathrm{ACTH}$, an effect that was most apparent in animals that received fetal betamethasone administration. This observation is consistent with alterations in anterior pituitary responsiveness. In contrast to the peak ACTH responses, NT, FS and MS animals did not exhibit any substantial 
changes in postnatal peak cortisol values from 6 months to 1 year. It is difficult to discern from these data whether pituitary responsiveness has increased due to a reduction in negative feedback or as a result of increased drive from the hypothalamus. It is clear, however, that although multiple doses of prenatal betamethasone have no effect, one single dose of betamethasone administered to either the mother or the fetus significantly elevated the 1 year peak cortisol levels compared with those at 6 months. Mechanisms by which a single dose of prenatal betamethasone would alter the developmental maturation of the sheep HPA axis are unknown, although it is possible that alterations in adrenal structure and function (as described earlier) could play a role. Further studies are required to understand whether these alterations are at the level of the hippocampus, hypothalamus, pituitary and/or the adrenal, with subsequent alterations in HPA function and negative feedback.

The differences between the effects of fetal and maternal glucocorticoid administration warrant further investigation. Our group has shown previously that maternal betamethasone administration resulted in significant reductions in fetal weight whereas fetal glucocorticoid administration did not (Newnham et al. 1999, Moss et al. 2000). These observations raise the possibility of an effect of maternal glucocorticoids on placental function, which in turn contributes to influences on growth, and potentially to HPA development.

In conclusion, we have found that prenatal betamethasone administration results in postnatal alterations in ovine HPA axis function that reflect exposure at discrete times in gestation and persist into adulthood. We speculate that these alterations in postnatal HPA axis function may contribute to the mechanisms by which adult health and diseases such as hypertension and diabetes are programmed in utero. In light of the number of studies linking alterations in the intrauterine environment with an increased risk of adult-onset disease, further studies seem warranted to understand the mechanisms linking early fetal events to postnatal health.

\section{Acknowledgements}

This work was supported by the Canadian Institutes and Health Research Group in Fetal and Neonatal Health and Development and the Womens and Infants Research Foundation at King Edward Memorial Hospital, Perth, Australia and the National Health and Medical Research Council of Australia (project grants 980578, 981406).

\section{References}

Ballard PL \& Ballard RA 1995 Scientific basis and therapeutic regimens for use of antenatal glucocorticoids. American Journal of Obstetrics and Gynecology 173 254-262.
Barker DJP 1998 In utero programming of chronic disease. Clinical Science 95 115-128.

Berry LM, Dolk DH, Ikegami M, Jobe AH, Padbury JF \& Ervin MG 1997 Preterm newborn lambs renal and cardiovascular responses after fetal or maternal antenatal betamethasone. American Journal of Physiology 272 R1972-R1979.

Boshier DP \& Holloway H 1989 Morphometric analyses of adrenal gland growth in fetal and neonatal sheep I. The adrenal cortex. Journal of Anatomy 167 1-14.

Brooks AN \&Challis JRG 1989 Effects of CRF, AVP and opioid peptides on pituitary adrenal responses in sheep. Peptides $\mathbf{1 0}$ 1291-1203.

Burton PJ \& Waddell BJ 1999 Dual function of $11 \beta$ hydroxysteroid dehydrogenase in placenta: modulating placental glucocorticoid passage and local steroid action. Biology of Reproduction 60 234-240.

Challis JRG \& Brooks AN 1989 Maturation and activation of hypothalamic-pituitary-adrenal function in fetal sheep. Endocrine Reviews 10 182-204.

Challis JRG, Huhtanen D, Sprague C, Mitchell BF \& Lye SJ 1985 Modulation by cortisol of adrenocorticotrophin-induced activation of adrenal function in fetal sheep. Endocrinology 116 1-6.

Challis JRG, Cox DB \& Sloboda DM 1999 Regulation of corticosteroids in the fetus: control of birth and influence of adult disease. Seminars in Neonatology 4 93-97.

Copper RL, Goldenberg RL, Das A, Elder N, Swain M, Norman G, Ramsey R, Cotroneo P, Collins BA, Johnson F, Jones P \& Meier A 1996 The preterm prediction study: maternal stress is associated with spontaneous preterm birth at less than thirty-five weeks gestation. American Journal of Obstetrics and Gynecology 175 1286-1292.

Edwards CRW, Benediktsson R, Lindsay RM \& Seckl JR 1993 Dysfunction of placental glucocorticoid barrier: link between fetal environment and adult hypertension? FEBS Letters 341 355-357.

Fletcher AJW, Goodfellow MR, Forhead AJ, Gardner DS, McGarrigle HHG, Fowden AL \& Giussani DA 2000 Low doses of dexamethasone suppress pituitary adrenal function but augment the glycemic response to acute hypoxemia in fetal sheep during late gestation. Pediatric Research 47 684-691.

Fraser M, Braems GA \& Challis JRG 2001 Developmental regulation of corticotrophin receptor (ACTH-R) gene expression in the adrenal gland of the ovine fetus and newborn lamb: effect of hypoxia during late pregnancy. Journal of Endocrinology 169 1-10.

French NP, Evans SF, Godfrey KM \& Newman JP 1999 Repeated antenatal corticosteroids: size at birth and subsequent development. American Journal of Obstetrics and Gynecology 180 114-121.

Hawkins P, Crowe C, McGarrigle HHG, Saito T, Ozaki T, Stratford L, Noakes DE \& Hanson MA 1998 Effect of maternal nutrient restriction in early gestation on hypothalamic pituitary adrenal axis responses during acute hypoxemia in late gestation fetal sheep. Experimental Physiology 85 85-96.

Hawkins P, Crowe C, McGarrigle HHG, Saito T, Ozaki T, Stratford L, Noakes DE \& Hanson MA 1999 Effect of maternal nutrient restriction in early gestation on development of the hypothalamic pituitary adrenal axis in fetal sheep at $0 \cdot 8-0 \cdot 9$ of gestation. Journal of Endocrinology 163 553-561.

Jeffray TM, Berdusco ETM, Wallace M, Fowden A \& Challis JRG 1995 Effects of incremental cortisol and adrenalectomy on plasma corticosteroid binding capacity in fetal sheep. Canadian Journal of Physiology and Pharmacology 73 1568-1573.

Jobe AH, Wada N, Berry LM, Ikegami M \& Ervic MG 1996 Single and repetitive maternal glucocorticoid exposures reduce fetal growth in sheep. American Journal of Obstetrics and Gynecology 178 880-885.

Jobe AH, Newnham J, Willett K, Sly P \& Ikegami M 1998 Fetal versus maternal and gestational age effects of repetitive antenatal glucocorticoids. Pediatrics 102 1116-1125. 
Johnson JW, Mitzner W, Beck JC, London WT, Sly DL, Lee PA, Khouzami VA \& Cavalieri RL 1981 Long-term effects of betamethasone on fetal development. American Journal of Obstetrics and Gynecology 141 1053-1064.

Langley-Evans SC, Gardner DS \& Jackson AA 1996 Maternal protein restriction influences the programming of the rat hypothalamicpituitary-adrenal axis. Journal of Nutrition 126 1578-1585.

Lanteri CJ, Willett KE, Kano S, Jobe AH, Ikegami M, Polk DH, Newnham J, Kohan R, Kelly R \& Sly P 1994 Time course of changes in lung mechanics following fetal steroid treatment. American Journal of Respiratory and Critical Care Medicine $\mathbf{1 5 0}$ 759-765.

Levitt NS, Lindsay RS, Holmes MC \& Seckl JR 1996 Dexamethasone in the last week of pregnancy attenuates hippocampal glucocorticoid receptor gene expression and elevates blood pressure in the adult offspring in the rat. Neuroendocrinology 64 412-419.

Liggins GC \& Howie RN 1972 A controlled trial of antepartum glucocorticoid treatment for prevention of the respiratory distress syndrome in premature infants. Pediatrics 50 515-525.

Lingas R, Dean F \& Matthews SG 1999 Maternal nutrient restriction $(48 \mathrm{H})$ modifies brain corticosteroid receptor expression and endocrine function in the fetal guinea pig. Brain Research $\mathbf{8 4 6}$ 236-242.

Matthews SG \& Challis JRG 1997 CRH and AVP-induced changes in synthesis and release of ACTH from the ovine fetal pituitary in vitro: negative influences of cortisol. Endocrine 6 293-300.

Moss TJ, Gurrin LC, Harding R \& Newnham JP 2000 Repeated prenatal maternal but not fetal, injections of corticosteroid reduce term birth weight, increase gestational length and cause a transient reduction in blood pressure during postnatal development in sheep. Journal of the Society for Gynecologic Investigation 7 192A.

Moss TJ, Sloboda DM, Gurrin LC, Harding R, Challis JRG \& Newnham JP 2001 Programming effects in sheep of prenatal growth restriction and glucocorticoid exposure. American Journal of Physiology. Regulatory, Integrative and Comparative Physiology 281 R960-R970.

Nathanielsz BW, Buster JE, Jenkin G, Jorgensen G \& Thorburn GD 1988 Induction of premature delivery in sheep following infusion of cortisol to the fetus: the effect of maternal progestagen on the C21-steroid-17ahydroxylase, C17, 20 lyase and aromatase pathways. Journal of Developmental Physiology 10 257-270.

Newnham JP, Evan SF, Godfrey ME, Huang WL, Ikegami M \& Jobe AH 1999 Maternal, but not fetal, administration of corticosteroids restricts fetal growth. Journal of Maternal and Fetal Medicine 8 81-87.

Norman LJ \& Challis JRG 1987 Synergism between systemic corticotrophin-releasing factor and arginine vasopressin on adrenocorticotrophin release in vivo varies as a function of gestational age in the ovine fetus. Endocrinology 120 1052-1058.

Norman LJ, Lye SJ, Wlodek ME \& Challis JRG 1985 Changes in pituitary responses to synthetic ovine corticotrophin releasing factor in fetal sheep. Canadian Journal of Physiology and Pharmacology 63 1398-1403.

Phillips DIW, Barker DJP, Fall CHD, Seckl JR, Whorwood CB, Wood PJ \& Walker BR 1998 Elevated plasma cortisol concentrations: a link between low birth weight and the insulin resistance syndrome? Journal of Clinical Endocrinology and Metabolism $83757-760$.

Picard-Hagen N, Penhoat A, Hue D, Jaillard C \& Durand P 1997 Glucocorticoids enhance corticotrophin receptor mRNA levels in ovine adrenocortical cells. Journal of Molecular Endocrinology 19 29-36.

Reinisch JM, Simon NG, Karow WG \& Gandelman R 1978 Prenatal exposure to prednisone in humans and animals retards intrauterine growth. Science 202 436-438.

Rose JC, Meis PJ, Urban RR \& Greiss FCJ 1982 In vivo evidence for increased adrenal sensitivity to adrenocorticotrophin (1-24) in the lamb fetus late in gestation. Endocrinology 111 80-85.

Seckl JR 1997 Glucocorticoids, feto-placental 11 $\beta$-hydroxysteroid dehydrogenase type 2, and the early life origins of adult disease. Steroids 62 89-94.

Siebe H, Baude G, Lichtenstein I, Wang D, Buhler H, Hoyer B-A \& Hierholzer K 1993 Metabolism of dexamethasone: sites and activity in mammalian tissues. Renal Physiology and Biochemistry 16 79-88.

Sloboda DM, Newnham J \& Challis JRG 2000a Effects of repeated maternal betamethasone administration on growth and hypothalamicpituitary-adrenal function of the ovine fetus at term. Journal of Endocrinology 165 79-91.

Sloboda DM, Newnham J, Gurrin LC \& Challis JRG 2000 b Prenatal programming of postnatal glucose tolerance in sheep. Journal of the Society for Gynecologic Investigation 7 192A.

Stewart PM, Murry BA \& Mason JI 1994 11ß-Hydroxysteroid dehydrogenase in human fetal tissues. Journal of Clinical Endocrinology and Metabolism 78 1529-1530.

Takahashi LK \& Kalin NH 1991 Early developmental and temporal characteristics of stress-induced secretion of pituitary adrenal hormones in prenatally stressed rat pups. Brain Research 558 75-78.

Uno H, Lohmiller L, Thieme C, Kemnitz JW, Engle MJ, Roecker EB \& Farrell PM 1990 Brain damage induced by prenatal exposure to dexamethasone in fetal rhesus macaques. I. Hippocampus. Developmental Brain Research 53 157-167.

Uno H, Eisele S, Sakai A, Shelton S, Baker E, DeJesus O \& Holden J 1994 Neurotoxicity of glucocorticoids in the primate brain. Hormones and Behavior 28 336-348.

Vallée M, Mayo W, Maccari S, Le Moal M \& Simon H 1996 Long-term effects of prenatal stress and handling on metabolic parameters; relationship to corticosterone secretion response. Brain Research 712 287-292.

Weinstock M, Matlina E, Maor GI, Rosen H \& McEwen BS 1992 Prenatal stress selectively alters the reactivity of the hypothalamicpituitary-adrenal system in the female rat. Brain Research $\mathbf{5 9 5}$ 195-200.

Wintour EM, Crawford R, McFarlane A, Moritz K \& Tangalakis K 1995 Regulation and function of the fetal adrenal gland in sheep. Endocrine Research 21 81-89.

Received 18 September 2001 Accepted 27 September 2001 